\title{
A CRITICAL ANALYSIS OF THE INDIAN AGRICULTURAL SECTOR- HOW TO RE-IGNITE THE HEARTBEAT OF THE INDIAN ECONOMY
}

\author{
Ishaan Roy, Vani Viswanathan, Manya Arora, Sanidhya Saraf and Shanay Ranka \\ Third year, Bachelor of Science in Economics, NMIMS, Mumbai \\ DOI: 10.46609/IJSSER.2020.v05i12.007 URL: https://doi.org/10.46609/IJSSER.2020.v05i12.007
}

\begin{abstract}
Agriculture has been known to be the most vital sector for the survival of the Indian economy. However, such importance is rapidly disappearing, with services being the kingpin of the Indian economy. Many argue that it is due to the changing preferences and behaviour patterns of millennial consumers, coupled with reducing dependence on a significantly volatile and susceptible primary sector. Nevertheless, one aspect that gets ignored in this discussion is the role of policies in enabling the position of agriculture as it is today. The focus of this paper is more on critically evaluating the effects of policies in enhancing the agricultural sector, mostly in terms of productivity and greater incomes for workers. The analysis of such policies indicated that the paper design of such policies looked spotless. Yet, a key practical issue was noticed in many of the policies, that is the lack of adequate implementation of such policies to desired target audience. Although causality between policy inefficiency and relative lagging efforts of agriculture were not quantified here, the analysis of these policies may indicate some truth behind the causal relationship. The policies were noted to be missing enough relevance to climate change, while also not satisfactorily creating awareness for insurance crops, coupled with the cost schedules of respective technologies related to climate variability, and the lack of proper methodologies for identification and verification process- which are a major part of implementation procedure. The biggest policy gap seen was the lack of relevance given towards the consumption and demand-side incentives, and that majority of the policies focus solely on the supply of agricultural produces. Based on these policy gaps, we proposed certain policies, which are as follows: Consumer Nudging, Climate Nudging, Insurance for All, AgriBuy App.
\end{abstract}

Keywords: Policies, Indian Agriculture, Farmers, Climate Change

\section{Introduction}

Agriculture is considered by many to be the heartbeat of the Indian economy, with this sector 
International Journal of Social Science and Economic Research

ISSN: 2455-8834

Volume:05, Issue:12 "December 2020"

being the primary source of income for around $58 \%$ of the population. Furthermore, the central and state revenue expenditure on agriculture amounts to over ₹4000 billion, as of FY18, with this amount expected to have increased, owing to the issues mentioned below.

Also, the GVA of the sector, which encompasses forestry and fishing, is at $\$ 265.61$ billion, as of FY19. Nevertheless, the share of agriculture, as a percentage of total GVA of India, has been reducing, from $18.6 \%$ in 2013-14 to $17.9 \%$ in 2016-17. This can be explained by an increasing demand for services and manufacturing, coupled with India's desire to move away from their volatile primary markets.

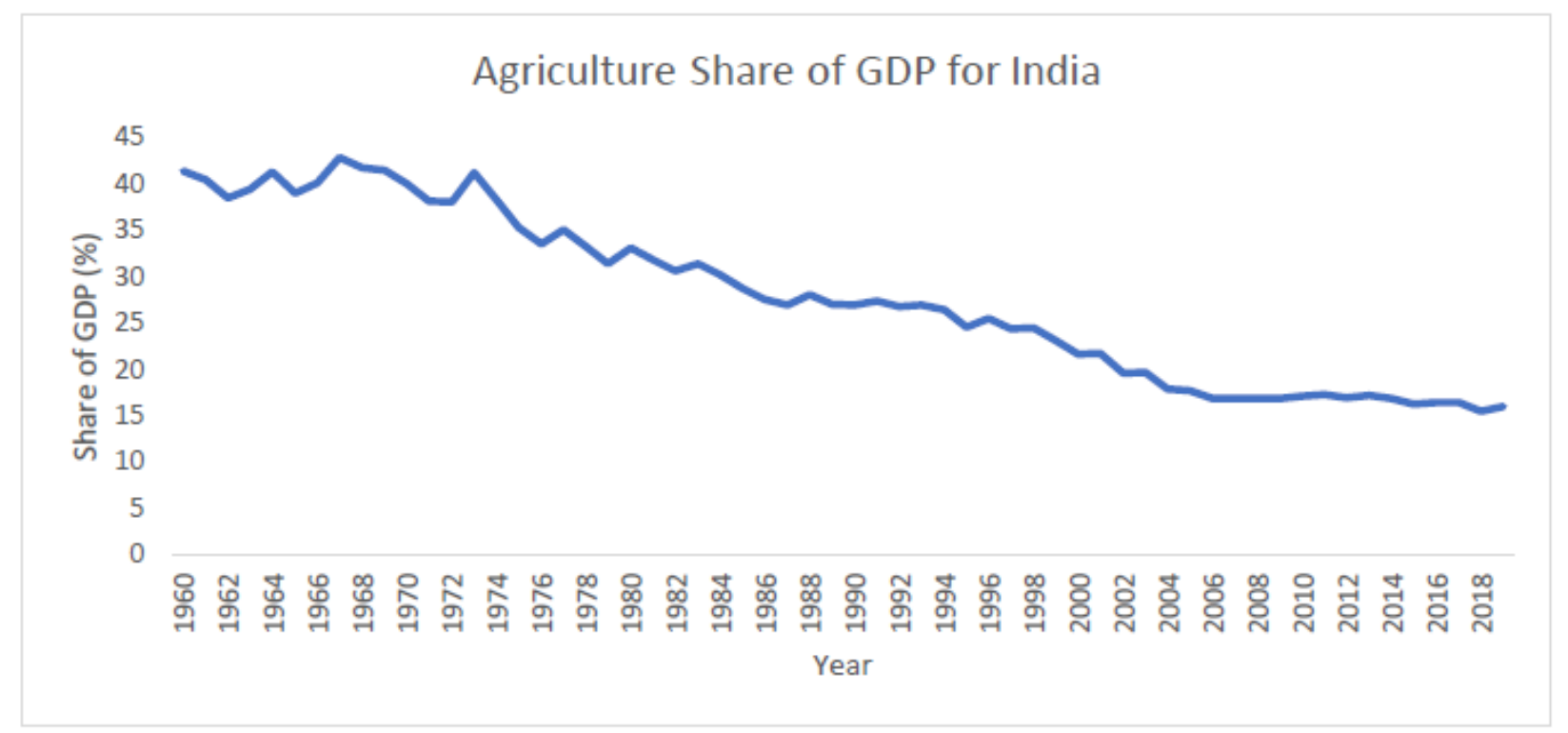

Source: World Bank

This indicates that as the years progress, the importance of agriculture will keep on diminishing, to such a point where India becomes a net importer of agricultural commodities. Even though the exports continue to rise, the rate at which they grow is diminishing, a significant fall from the rapid growth of the early 2000s. Nevertheless, the continuous schemes provided by the current government, along with the various backings of the Prime Minister, Narendra Modi, the agriculture sector still holds significant relevance, as of now.

However, in spite of the numerous schemes and plans that have been rolled out by this government, some issues still persist- most notably the unproductivity of loan waivers, the lack of digital exposure for the rural people, inadequate food self-sufficiency and an increasing trend of farmer distress and suicides, as the years progress. Such pressing issues have also helped in forcing the reality that India may need to move away from the dependence of the agriculture 
sector, to continue their battle with China to be the world's fastest growing economy. This is made evident by the below graph, where India's contribution to GDP is being influenced more by services, while agriculture's influence is reducing.

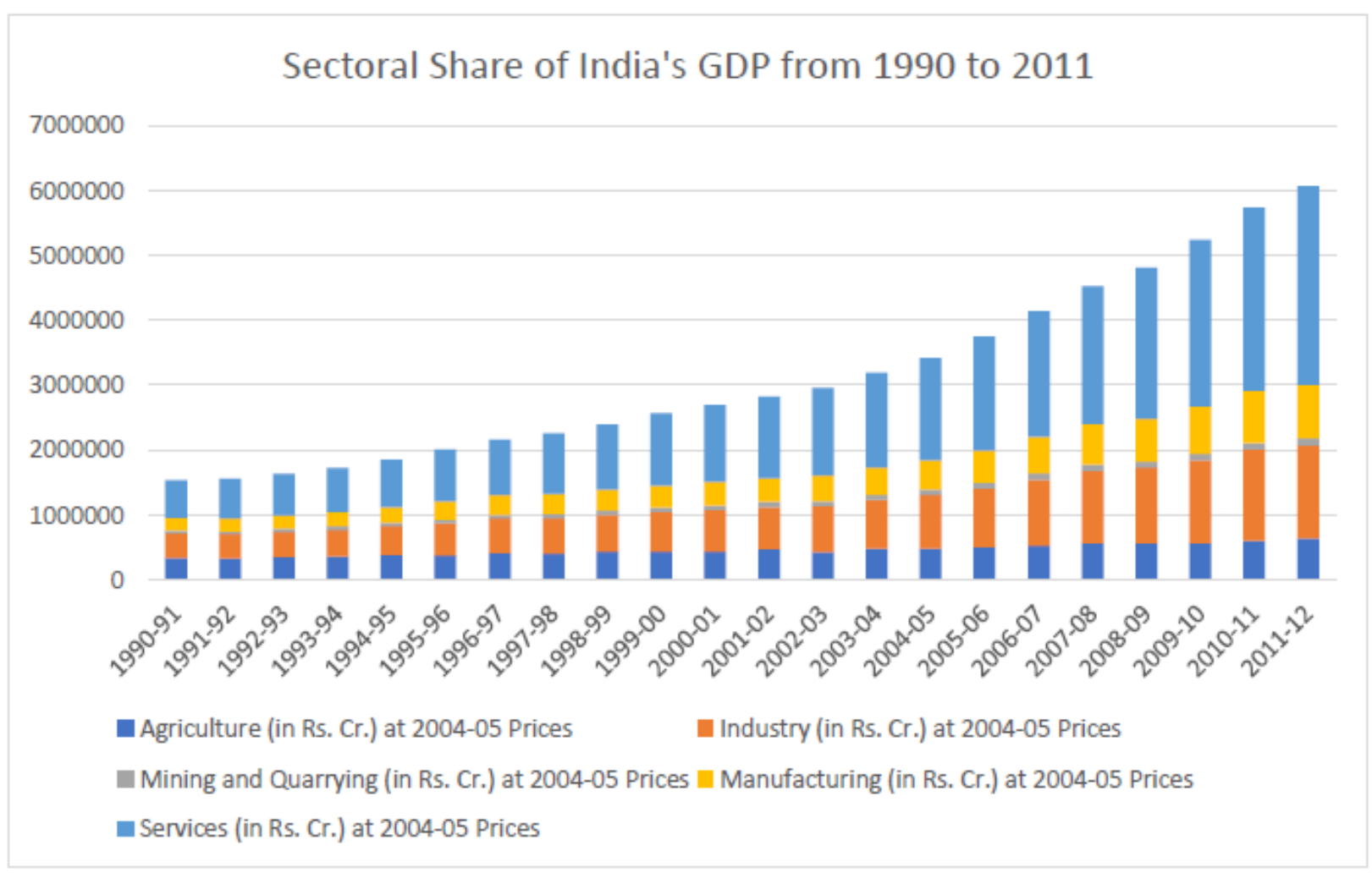

Source: data.gov.in

This document will look at the major components missing from the main agricultural policies of the $21^{\text {st }}$ century, along with any other policy gaps that exist in the sector. From this, we will be suggesting the type of policies that need to be implemented to overcome the issues that are plaguing this sector. These policy suggestions are more indicative about the broad ideology that they should follow, rather than suggesting the implementation of specific policies mentioned below.

\section{Policy Gaps in The Agriculture Sector}

For most of the agricultural policies, they have had some degree of success, mostly in conjunction with other policies, in improving the state of the agricultural sector, in terms of productivity, maximum yield cultivable and in improving the livelihoods of farmers.

However, such effects have only been seen for a small minority of farmers, majority of whom 


\section{International Journal of Social Science and Economic Research}

ISSN: $2455-8834$

Volume:05, Issue:12 "December 2020"

are non-marginal farmers ${ }^{1}$. Furthermore, given the reducing yields of the agricultural sector, and the decreasing importance of this sector in boosting the Indian economy, it can be inferred that the policies implemented are not capable enough of re-vitalizing this sector.

Additionally, given the high correlation between the agriculture sector's growth rate and the economy's growth ${ }^{2}$, a low growth rate in this sector has not bode well for the economy.

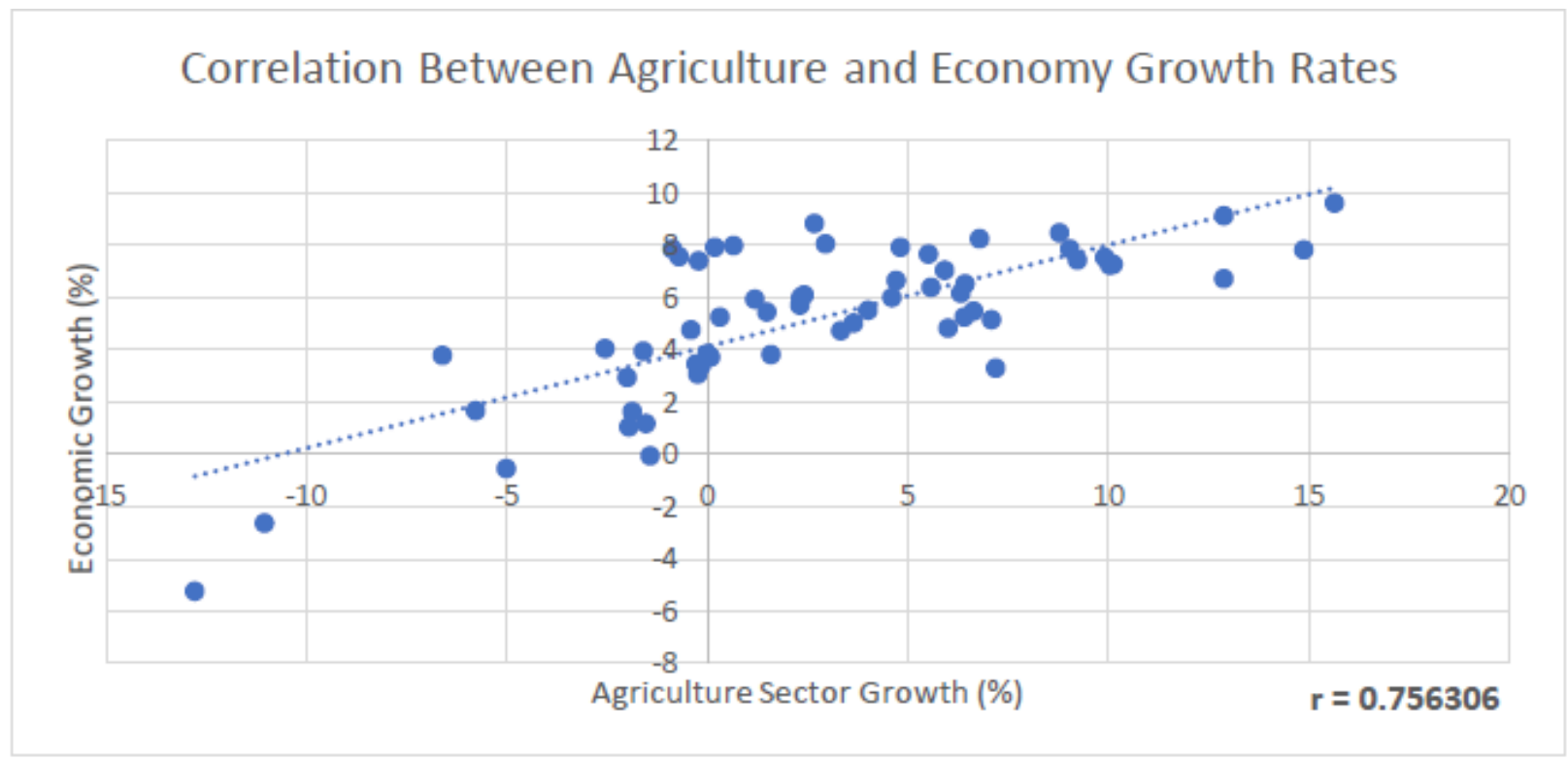

Source: World Bank

One of the primary issues faced in many of the policies was the complete dispersion of funds, as allocated under the Budget. Although the Budget announces a proposed funding for each policy, it should be taken with a pinch of salt- since most policies, especially in agriculture, do not tend to receive the funding as mentioned in the Budget. This is primarily due to lack of fiscal prudence, combined with the recent increased efforts of revitalizing the Indian economy from domestic and global slowdown. For most developing countries, government expenditure for boosting an economy goes to sectors that have greater interlinkages and higher value-added goods and services. Since agriculture does not have significant inter- linkages, and its main produce are volatile primary goods, the expenditure is less focused on agricultural aspects. Therefore, when actualized spending is taken into consideration, this figure, in recent years, has been less than the proposed numbers in the Budget announcement.

\footnotetext{
${ }^{1}$ Farmers who operate on more than 2 hectares of land

${ }^{2}$ Indicated by the relatively high correlation value mentioned in the bottom right area of the graph
} 


\section{International Journal of Social Science and Economic Research}

ISSN: $2455-8834$

Volume:05, Issue:12 "December 2020"

Nevertheless, one aspect of funding that these policies do not consider is the influence that governmental institutions play in enabling policies to be impactful. The point being made here is that if such governmental institutions start to focus on other priorities or are unable to create the same impacts as necessary, then the there are no contingency plans that are set, to combat this debacle. The example of the Food Corporation of India (FCI) serves as an apt example to explain this phenomenon. FCI essentially purchases rice and wheat directly from farmers. They purchase this at MRP and sell the grains at extremely low prices through the public distribution system, which facilitates the requirements of food security. However, this creates a substantial loss for the organization. To compensate this, the government repay the organization the deficit amount, to ensure the continued functionality of the program.

However, with lower than expected tax growth, combined with enlarging fiscal deficit, the government does not necessarily pay back the deficit amount. In 2018-19, around ₹1.71 trillion was earmarked to be utilized for food subsidies. However, due to previously mentioned reasons, a revised allocation of ₹ 1.02 trillion was made. Given that actualized allocation is always less than proposed allocation, they likely got less than ₹ 1 trillion. The total food subsidy that FCI had to provide was ₹2.61 trillion, for the same period, meaning that around ₹1.6 trillion was owed by the government. They get some of this amount by borrowing through NSSF. FCI received ₹94000 crore from NSSF in the same year. However, for NSSF to continue providing funds to FCI, they needed higher deposits. Yet, with interest rates being reduced drastically, due to the accommodative stance of the Monetary Policy Committee, it has attracted less deposits into the NSSF. Due to this, NSSF have less funds, meaning that the deficit may not be paid out by borrowing from such sources, or through government expenditure ${ }^{3}$, resulting in uncertainty about there being a set buyer to free farmers of their surplus crops.

This suggests how most of the policies have focused on agriculture from the supply-side, and not paid enough attention towards enhancing or continuously maintain demand. If the demand disappears (if the deficit cannot be repaid by other parties, in the case of FCI), then supply aspects become irrelevant. Most of the policies mentioned here are concerned with how to improve efficiency of agricultural fields and workers, while also providing them with monetary incentives to continue producing their goods, or to utilize better technology. This is exemplified by the policies of PM-Kisan, National Initiative of Climate Resilient Agriculture, Pradhan Mantri Krishi Sinchayee Yojana and Pradhan Mantri Fasal Bima Yojana. Most of these are relevant topics in the current agricultural scenario, but they all focus on the supply- side aspects of agriculture. There are hardly any relevant policies that describe demand aspects of agriculture, such as demand-side incentives, buyers' preferences and combining the production of

${ }^{3}$ Given the increasing trend of the current government exceeding the proposed fiscal deficit targets 


\section{International Journal of Social Science and Economic Research}

ISSN: $2455-8834$

Volume:05, Issue:12 "December 2020"

agricultural workers with the utility of the buyers of the other party's produces. This is elucidated by the two-way approach to policy reforms that the government are planning to implement- with the focus being solely on supply-side reforms ${ }^{4}$. Also, the lack of focus on demand has led to prices collapsing ${ }^{5}$, which adversely affect the farmer's ability to increase their incomes. The issue of creation of demand is one of the most significant aspects that most policies seem to have missed out one, and our policy suggestions would be mainly based on this.

This issue is compounded by a lack of recognition given towards middlemen, in heightening prices to exorbitant levels, when comparing prices that farmers receive to prices that consumers pay for the same produce that these farmers produce. Most of the agricultural policies do not mention the middlemen as one of the deterrents to progression in earning of income. Furthermore, majority of the farmers are small and marginal farmers, which consist of $86.2 \%$ of all farmers, and these people lack access to government facilities due to reasons ranging from low individual agriculture surplus, delays in payments to beneficiaries and ungainly bureaucratic process. This leaves farmers with no option but to sell their produce to middlemen, while zero to little profit in this process.

Another aspect that was missing from these policies was the implications of climate change. Except for NICRA, which is still not the perfect answer for climate variability in agriculture, most of the policies fail to account for the somewhat-uncontrollable effects of this phenomenon. Most of the policies believe that it is an issue of incentive that causes decreasing yields in this sector. However, as correctly pointed out by NICRA, climate change does play a significant role in this reduction of yields. Around 60000 farmer suicides have occurred over the last 10 years, directly and indirectly caused by this ghastly phenomenon.

Furthermore, there has hardly been any mention of environment or climate change in these policies, and one policy that has discussed about these concepts is the National Agriculture Policy, which was implemented in 2000- when climate change was not known for its rampaging effects, but as at the possibility of harming the ecosystem. Furthermore, in the policies that discuss these ideas, most of them just talk about resolving this issue, and not talking about how to do it- with National Agriculture Policy being the most apt example for this.

Moreover, these policies talk about investing in new technologies and/or infrastructure to boost

\footnotetext{
${ }^{4}$ One way looks at farmer welfare, structural modifications and increasing farmer's income, while the other approach looks at improving efficiency, productivity, and output throughout the agriculture business

${ }^{5}$ There was a surplus of 50 million tonnes of food grains, however, the lack of creation of demand has meant that this is being stored in government warehouses, rather than being purchased by Indian households
} 


\section{International Journal of Social Science and Economic Research}

ISSN: $2455-8834$

Volume:05, Issue:12 "December 2020"

agricultural yields. However, these policies assume that such investments have not been made or have not been substantial. However, the policies of RKVY and NICRA prove that this is not the situation. Nonetheless, in the eNAM policy, initiatives are present and have the potential to fulfil its goals, but this is being hampered by lack of adequate physical infrastructure. The technologies and infrastructure introduced by these policies probably have been inducted, but this has not led to agricultural yields boosting, or productivity improving, or farmers' income doubling. This is primarily due to a surplus of such investments- with such infrastructure and/or technologies being present in the agricultural ecosystem, but not being utilized efficiently enough, or have been left underused. Rather than focusing on improving and fixing this situation, which would be arguably cheaper, than introducing new machineries. Also, it is necessary to radicalize such investments- to match the high-tech concepts that other countries are implementing in their respective agriculture sectors. India is lagging behind, in terms of technology, and its resolutions should incorporate the ideologies included in the plans of countries with recent success in modernized agriculture- and these need to be mentioned in the policies ${ }^{6}$.

Another issue faced is the lack of importance given to insurance, especially given the increasing drastic measures taken by farmers, as years keep on progressing. The National Food Security Mission's implementation highlighted the government's challenge to induce higher acceptance of crop insurance, while PMFBY talked about the specific cases ${ }^{7}$, insinuating lack of national coverage and success. Furthermore, there is a lack of knowledge about such insurance-related schemes. Insurance for crops need to be given greater importance, given that more crops are being lost due to uncontrollable factors. Given that the earnings from agriculture are menial, farmers feel the need to invest their earnings into necessities, rather than other aspects, like crop insurance. This is even more prevalent given that farmers, on average, spend $30 \%$ of their revenue on inputs, especially fertilizers and labour costs. Given such expenditure, there is a sense of belief that such spending would be given an assurance that crops would be cultivated adequately. However, with farmers not choosing to utilize machineries that can combat climate variability, but not as effectively as possible. Also, these investments are more expensive than their current investments. This does not make economic sense for farmers, and ultimately leads to crops being lost due to climate change ${ }^{8}$. In such a situation, insurance is vital, to ensure that investments are repaid.

Other than this, it is the quality of the policy that means that insurance can be considered as a policy gap, even though a separate policy exists for this exact purpose. Around 66\% of households were not aware of the existence of such insurance schemes, while $21 \%$ were unhappy

\footnotetext{
${ }^{6}$ Since there are hardly any ideas derived from such sources

${ }^{7}$ Bihar and Uttar Pradesh were discussed prominently in the policy description

${ }^{8}$ This is not the sole factor for the lower yields
} 


\section{International Journal of Social Science and Economic Research}

ISSN: $2455-8834$

Volume:05, Issue:12 "December 2020"

with the terms and conditions of the policy. Additionally, under the PMFBY, insurance is available only for food, oilseeds, and horticulture crops, which encompass around $30 \%$ of total crop loans dispersed by banks. This is another potential reason for a lack of awareness for these kinds of scheme- lack of coverage of crops. Also, a study by Meenakshi Rajeev and Pranav Nagendran explain that insurance failure ${ }^{9}$ exists due to the design of the insurance schemes. Therefore, the economic structuring of insurance schemes, along with its implementation and design are the reasons why insurance, as described in the few policies, haven't necessarily worked, and can be termed as one of the things that these policies are missing.

Lastly, when such universal national policies are implemented, we see that such policies tend to be skewed towards bigger states. This is particularly prevalent towards the agricultural sector, and the scheme of Minimum Support Price is an apt example to indicate this situation. Procurement under MSP tends to be dominated by wheat and rice. This means that around half of the procurement arises from Punjab and Haryana, and an additional 40\% are procured from the states of Andhra Pradesh, Madhya Pradesh, Uttar Pradesh, Odisha, and Chhattisgarh. The other states hardly engage in the same level of procurement that the above- mentioned states engage in. This is especially relevant for North Eastern states, where access to such government procurement facilities are far more limited to them, as compared to any other region in the country. This situation is amplified when considering the access to infrastructure and tools, as indicated by the fact that $42 \%$ of the states utilize $85 \%$ of the total fertilizers present to the Indian agriculture. Although this factoid is from 2016, such skewness has not been recognized, and, therefore, it would not be surprising if such concentration even increased. However, we can say with surety that a lack of policy recognition on these aspects would at least maintain such concentration towards states that are allocated higher access and greater funds for indulging in more efficient agricultural activity. In reality, funds and access to governmental and other resources should be handed based on the evaluation of the tools and infrastructure present in each state. States that are significantly worse-off in these aspects, like the North-Eastern states, need to be given proportionately more funding and access than to Northern states, where infrastructure and availability of tools are not an issue.

Given the several implications that most of the agricultural policies fail to highlight about the state of the sector, we have proposed a few policies to resolve these issues. The policy suggestions mentioned below are brief description of what the type of policy should be and how it should be conducted.

\footnotetext{
${ }^{9}$ In $2017-18$, coverage, measured in terms of cultivable land, reduced to $26 \%$, from $29 \%$ - a far cry from the target of $50 \%$
} 
International Journal of Social Science and Economic Research

ISSN: 2455-8834

Volume:05, Issue:12 "December 2020"

\section{Policy Suggestions for The Agriculture Sector}

In the previous section, we highlighted issues related to lack of creation of demand, inadequate verification and identification process, insufficient relevance for climate change, inability to adequately intervene- in terms of infrastructure and technologies- and lack of awareness and coverage for insurance of crops.

We will be tackling each of these policy gaps individually, to determine the best possible solution to fully resolve this gap, rather than achieving only half of the objectives of all these policy gaps.

\section{Creation of Demand/Existence of Excess Supply \& Middlemen.}

The major policy suggestion for this issue is Consumer Nudging. This policy would aim to utilize the basic concepts of behavioural economics to maximize the demand for agricultural produces, given the increasing likelihood of the inability to repay adequate amount of debts of the FCI. We propose that through the implementation of such a policy, citizens are likely to become more aware and pro-social about their actions once their private information becomes available in the public domain. Furthermore, this should be governed by the panchayats in charge in different classified backward villages, while the more developed rural areas' activities will be administered by zila parishads, while urban areas' actions would be monitored by municipal corporations. Additionally, incentives would be given to consumers, to increase purchase of such goods.

Initially this role of administration would be given primarily to the Residential Welfare Association, for urban and developed rural areas, and panchayats. There would be monetary incentives provided, which would consist of discounts and cashbacks, mainly available through consumer bulk-buying. Once a set amount of purchase has been conducted by a consumer, they would receive a call from their respective governing body informing them about their purchase of agricultural produce- which would include specifications of the quantity, price of previous purchases and future viability of future purchases. This data would be collected for each individual and would be circulated separately by these organizations, showing their net expenditure and their closest rival applicable in their living area. Given that cashbacks and or discounts are available for both individual purchases and final positioning of a consumer, in terms of purchases, this sense of competition tends to create an optimal and efficient equilibrium outcome. These outcomes happen given that the governing bodies of the respective localities host an event where they acknowledge such contributors to the agrarian society, and their contributions would be rewarded- incentivizing others to become a leading contributor as well. 


\section{International Journal of Social Science and Economic Research}

ISSN: $2455-8834$

Volume:05, Issue:12 "December 2020"

The primary objective of this policy would be to increase the domestic private consumer base of the agricultural harvests that farmers produce, while also reducing the level of surplus that farmers produce. Additionally, by reducing the surplus of these harvests, it would lead to lower storage costing, and lower deficits for the government, meaning that these costs can be transferred towards implementing this policy.

Furthermore, this can be streamlined into an app, i.e. The AgriBuy App. The data collection procedure and can be an alternate source for households to continuously monitor their agricultural purchase of agricultural produce. Furthermore, the data tabulated from the above policy suggestion would be inputted into this app in the same manner. The app will also ask for other economic indicators of the person and can accordingly determine the amount of agricultural produce necessary for them, while also indicating the number of cashback/discounts available to them for a certain amount of purchases. If the acknowledgement event is considered to be too tedious to be held in urban and developed rural areas, then this policy can be used to reward consumers with the same incentives. Note that once purchases and/or consumer position has been finalized and ratified to be accurate, the recipient would receive cashbacks or discounts through the BHIM App.

These two policies are favourable towards the farmers and the consumers due to the removal of several middlemen, in this process. Middlemen tend to increase the prices of agricultural produces, which leaves farmers receiving only a fraction of the price that consumers pay, and consumers pay more than what farmers receive. By removing the middlemen in these policies, it would lead to a pareto optimal solution for consumers and producers- given that prices would fall, relative to price that consumers pay to such a point that both consumers and producers receive a better price for their respective needs. Furthermore, by increasing access to governmental procurement resources to farmers, it gives them another avenue to sell their goods to, which is made all the more prevalent with reducing importance that the government gives to middlemen in this policy- which essentially leads to the eradication of the former, at least in this proposed system. This also implies that the administration of transactions, coupled with pricing and quantity regulations need to be supervised by the monitoring bodies mentioned for Consumer Nudging.

\section{Verification and Identification Process.}

To resolve the issue of verification and identification process, especially in terms of operation of land, we suggest streamlining and further development of JAM Trinity, which links Jan Dhan accounts with mobile numbers and Aadhaar cards- as means to prevent the leakages of government subsidies. 


\section{International Journal of Social Science and Economic Research}

ISSN: $2455-8834$

Volume:05, Issue:12 "December 2020"

As of January 2019, 33 crore Jan Dhan accounts were opened and 123 crore Aadhaar numbers were registered. These above factoids illustrate the enormous headway that this policy has made in the short time since it was implemented. However, given the adverse leakage and beneficiary recipient implications of Direct Benefit Transfers, one of the primary subsidy provision policies in India, the normalization of JAM trinity is a must. This is possible, given that majority of rural citizens are exposed to technology mentioned under this scheme, where around 499 million of 875 million rural people own mobile phones, as of 2017. This coverage ratio can be assumed to have increased, given the importance of digitization that Prime Minister Modi has placed in his regime.

This streamlining will ensure that the beneficiaries receive the proper grants that they are eligible to receive, provided that they are registered under the Aadhaar database. Such digital recordkeeping will minimize the errors of passing on grants to incorrect recipients.

Consequently, this also minimizes the issue of government subsidy leakages present in the agrarian situation. This would ensure that policies like PM-Kisan and Direct Benefit

Transfers can rightfully pass on the accurate amounts of grants towards the correct beneficiaries. Essentially, through streamlining of Aadhaar registration, while shifting away from analogous data recording can reduce the data inconsistencies of verification and identification. The former point creates a popular misconception, that majority of Indian households hold Aadhaar cards. However, given that only $7 \%$ of rural households know about the total procedure of Aadhaar authentication process, indicating a low level of exposure, regarding Aadhaar identification in rural areas. Therefore, it is imperative to resolve this issue by the government officials registering rural households themselves, rather than waiting for these people to register themselves- considering the asymmetric information for these households.

\section{Relevance of Climate Change \& Infrastructure and Technology.}

To increase the relevance of climate change, there needs to be more campaigns raising awareness about the adverse impacts of the phenomenon, while also providing mandatory education about the topic. Furthermore, it should be made compulsory for farmers to utilize machineries that combat climate variability. As mentioned previously, the payments of maintenance and repairs of such equipment should be linked with schemes under Direct Benefit Transfers. For this, we can implement a similar policy to Consumption Nudging. In this scenario, the farmers are considered to be consumers, and their purchase products would consist solely of climate change related infrastructure and technology, such as flux towers.

Naming this policy Climate Nudging, it revolves around the same principles of Consumer 


\section{International Journal of Social Science and Economic Research}

ISSN: $2455-8834$

Volume:05, Issue:12 "December 2020"

Nudging, where farmers would function more efficiently and have a greater incentive to purchase these goods given that their information is made public, and they are competing with other farmers to reduce their increased costs, as means to improve their profitability of their crops.

Farmers will receive discounts on repairs if they purchase more climate change related machineries per hectare. Such payments would be made through the BHIM App, where a special interface should be created, to incorporate these aspects, while also including the discounting calculations necessary for farmers to pay for these variable costs. However, there should be a limit on the amount of machineries per hectare permitted to be acquired by these farmers, given the possibilities of overproduction and the opportunity cost of excess utilization. Since this limit exists, it should be limited on a hectare basis. The maintenance and repair data will be collected by officials of NICRA, and a sheet will be given to them on a bi-annual basis, indicating their repair cost. Furthermore, experts will visit such fields once every three months, to check on the machineries and provide an estimate for repairs, excluding for discounts, to these farmers and indicating the increase in yield capacity through proper utilization of such purchased machinery.

The data will be circulated with information about their repair costs, combined with their quantity of agricultural harvest produced in the same period. This is done to ensure that if repair costs are high, it is correlated with higher agricultural yield, and not that these costs are high because they have purposely broken these machines down and have only employed such machinery for availing the discounts. Also, the same data will be illustrated for their neighbours and close-by rivals. This is done to foster competition, as means to increase the level of production. This would be beneficial if this works in conjunction with Consumption Nudging and if these machineries are being utilized.

Ultimately, on an annual basis, these farmers would be invited to an acknowledgment event, where the top harvesters would be given monetary prizes. We emphasise that the winners would be the top harvesters, and not people who have incurred the highest costs. The repair costs are used as indicator to clarify the level of harvests for each farmer.

In this situation, repair and maintenance costs are included in provisioning of discounts to incentivize farmers to include modernized technology to combat the uncontrollable factor of climate change. For individual situations of necessary refurbishments, discounts would be provided, but monetary incentives, on a large scale, are provided solely to people who have cultivate the greatest number of crops per hectare, rather than accumulating such costs.

Additionally, given that technology mentioned above has solely focused on climate change, India needs to incorporate such technologies into more agricultural fields. The emphasis should be 


\section{International Journal of Social Science and Economic Research}

ISSN: $2455-8834$

Volume:05, Issue:12 "December 2020"

more on combatting climate change, rather than installing machineries with greater productivitygiven that more crops are becoming futile due to a lack of recognition to climate change, and not due to the latter factor. Given that India still lags behind in production of such infrastructure and technology, it is advisable to import such technology from European countries like France, United Kingdom and Switzerland, for example. Such heavy investments are necessary to sustain the integrity and vitality of the agricultural sector and ensuring that agrarian distress is minimized by tackling the core issue.

Finally, when allocating such technology and infrastructure to different states, an evaluation regarding these aspects should be made by experts- as to understand which states and regions are in greater need of such resources. Given the treacherous conditions of the North-Eastern regions, combined with a lack of effort being made towards improving necessary infrastructure, such as cold storage infrastructure, they should be considered, when allocating such technologies. The decision of allocation needs to be made based on need, functionality in the particular region, and the added marginal private and social benefit that it can provide to the individual and to the society, respectively.

\section{Insurance for Crop Yields.}

The main issue with insurance for crops is the lack of coverage present for the entirety of crops, combined with a lack of awareness about the existence of insurance schemes.

To combat this, we propose to implement the Insurance for All. This includes providing insurance for all types of crops, while going from doorstep to doorstep to inform rural households about the existence of such schemes, while also explaining the benefits of having insurance, especially with the adversity of climate change ever-increasing.

The latter aspect can be conducted by re-forming the Business Correspondent Model, which can be considered as the crux to this policy. In this model, a person previously acted as a middleman between banking companies and rural households, but now, the banking companies are replaced with insurance companies. Furthermore, to not increase the price of insurance, the middleman is an employee of the company that is allocated to work in these rural areas. One of the major issues with previous model was that banks could build simple brick and mortar structure, but they could only build this in places with a population of above 2000 people. Less than $5 \%$ of these villages fit this description, which made it economically unfeasible for banks to create such structures. However, this newer model for insurance will propose that insurance companies must compulsorily build a brick and mortar structure if this structure is within a 25-kilometre radius from a village with a population of 500 permanent residents. Given that around $80 \%$ of customers got to know about the intricacies of Pradhan Mantri Jan Dhan Yojana (PMJDY) 


\section{International Journal of Social Science and Economic Research}

ISSN: $2455-8834$

Volume:05, Issue:12 "December 2020"

through such correspondents, a similar response can be expected from the implementation of this policy for insurance.

Another issue with this model was that forged bank accounts that were opened by BCs. Around $20 \%$ of business correspondents faced fraud, while $33 \%$ of the bank accounts were duplicates. This was done as BCs were unable to attract customers, so they opened bank accounts in their name, in order to earn more income, by receiving more commission as more bank accounts were opened. To combat this issue, insurance will be provided in conjunction with Aadhaar verification, while a consent form will be signed by the recipient of insurance, and will be verified with the Aadhaar database, for the information and details to not be forged.

This policy ensures that rural households receive information about insurance of their respective crops, while the inclusion of all crops under this policy significantly increases the coverage ratio of farmers having crops. Lastly, through purchase of insurance for all their crops, they would be eligible to receive other types of insurance, such as fire insurance or rider insurance, at a discounted rate. Such additional incentives could be provided if they are unsure about ensuring their crops due to the variable costs attached to it.

\section{Conclusion}

The present agricultural policies in place have had some success, only to a certain extent. Due to inadequate ability to rectify infrastructure issues, lack of recognition for demand-side polices, insignificant verification and identification process, the heightening of price due to middlemen, the lack of coverage for crop insurance and the lack of relative importance assigned towards climate change are some of caveats of the agricultural sector that hasn't been completely addressed in policies, or have been addressed in the paper design, but hasn't been implemented adequately.

To combat such issues, we proposed the streamlining of Aadhaar, through greater penetration of the JAN Trinity, while also introducing Consumer Nudging and Climate Nudging, which aim to provide greater private consumer demand and to heighten the relevance of climate change to farmers, respectively. In addition to Consumer Nudging, the AgriBuy App was proposed, which would have the same functions as Consumer Nudging, but would be implemented digitally, and its penetration is focus solely towards urban and developed rural areas. Furthermore, India should increase its imports of climate resilient technology from environmentally friendly countries, like European countries of France and United Kingdom, given that India are laggingin terms of manufacturing these modernized types of technology. Finally, we introduced the Insurance for All policy, where the crux is explained by the Business Correspondent Modelwhich would directly accumulate customers from rural households, and provide them with 


\section{International Journal of Social Science and Economic Research}

ISSN: $2455-8834$

Volume:05, Issue:12 "December 2020"

information about crop insurance, while also providing insurance for all types of crops- one of the major drawbacks of the existing policies in place.

It is important to note that majority of these policies need to work in conjunction, and if they are implemented solitarily, then their outcomes would be lower than their potential ${ }^{10}$.

Through implementation of such policies, we expect majority of the stated policy gaps to be resolved, while it could transform the agriculture sector into major hub of prosperous livelihood that it once was for majority of the rural households. Although not all the problems would be resolved through these policies, these policy suggestions should hold the agriculture sector in good stead and should progress the productivity and efficiency of the lagging sector to new heights.

\section{Acknowledgment}

We would like to thank Professor Anu Abraham for giving us the opportunity, resources, and linkages to work on this project. We are gratuitous for the help and guidance that she has provided us in every step involved in arriving at this report. Without her inputs, this report would not have been possible.

\section{Bibliography}

$42 \%$ of India's districts use $85 \%$ of its chemical fertilisers. (2016, August 12). Retrieved from https://www.downtoearth.org.in/news/agriculture/42-of-india-s-districts-use-85-of-its- chemicalfertilisers-55267

6 reasons why India has failed to solve the riddle of agriculture marketing. (2019, January 6). Retrieved from https://www.downtoearth.org.in/news/agriculture/6-reasons-why-india-hasfailed-to-solve-the-riddle-of-agriculture-marketing-62712

Agriculture sector may be due for a policy revamp, say experts. (2019, June 28). Retrieved from https://www.thehindubusinessline.com/news/agriculture-sector-may-be-due-for-a-policyrevamp-say-experts/article28211133.ece

Alexander, S. (2019, July 10). Crop insurance schemes need better planning. Retrieved from https://www.livemint.com/industry/agriculture/why-crop-insurance-needs-to-be-betterdesigned-1562741755465.html

${ }^{10}$ If they are combined with the proposed policy suggestions 


\section{International Journal of Social Science and Economic Research}

ISSN: $2455-8834$

Volume:05, Issue:12 "December 2020"

Bhide, S. (2018, March 9). The 'demand' side of agriculture. Retrieved from https://www.thehindubusinessline.com/opinion/columns/shashanka-bhide/the-demand-side- ofagriculture/article20371409.ece

Decoding Slowdown: Govt apathy and low investment continue to plague the agriculture sector. (2019, September 27). Retrieved March 10, 2020, from

https://www.businesstoday.in/sectors/agriculture/decoding-slowdown-agriculture-sector- govtapathy-low-investment-plagues-farmers-income/story/381618.html

Financial inclusion and BC Model in India - Progress So Far. (2018, September 26). Retrieved from https://www.sesameindia.com/blog/financial-inclusion-bc-model-india-progress-far/

India Brand Equity Foundation. (2017, July 17). Analysis About Indian Agriculture Industry, Market Size, Export \& Investment Opportunity. Retrieved March 10, 2020, from https://www.ibef.org/industry/agriculture-india.aspx

India's Biggest Challenge: The Future of Farming. (2019, October 1). Retrieved from https://www.theindiaforum.in/article/india-s-biggest-challenge-future-farming

JAM trinity has changed the financial landscape completely: Ashishkumar Chauhan. (2018, March 17). Retrieved from https://economictimes.indiatimes.com/markets/expert-view/jamtrinity-has-changed-the-financial-landscape-completely-ashishkumarchauhan/articleshow/63343627.cms?from=mdr

Kaul, V. (2019, August 6). Interest rates are unlikely to go down. Retrieved from https://www.livemint.com/industry/banking/interest-rates-are-unlikely-to-go-down1565022491722.html

Kulkarni, A. (2017, June 15). Modi Government's Skewed Farm Sector Priorities Continue to Cause Farmer Distress. Retrieved from https://thewire.in/agriculture/skewed-priorities-farmsector

Metcalfe, R. (2018, November 6). Using Multiple Social Nudges to Reduce Peak Energy Demand. Retrieved from https://www.behavioraleconomics.com/using-multiple-social- nudgesto-reduce-peak-energy-demand/

Mishra, A. R., \& Gupta, K. (2018, February 14). Over $20 \%$ of business correspondents faced fraud in 2017: MicroSave report. Retrieved from https://www.livemint.com/Industry/4jL1r9XnS43BbwdEOZEVLO/Over-20-of-businesscorrespondents-faced-fraud-in-2017-Mic.html 


\section{International Journal of Social Science and Economic Research}

ISSN: $2455-8834$

Volume:05, Issue:12 "December 2020"

Padhee, A. (2020, February 3). Agriculture in Budget 2020: Implementation key to make a real difference. Retrieved from https://timesofindia.indiatimes.com/blogs/voices/agriculture-inbudget-2020-implementation-key-to-make-a-real-difference/

Ramanathan, A. (2020, January 31). What Budget 2020 can do for the agriculture sector.Retrieved from https://www.livemint.com/budget/expectations/what-budget-2020-can-dofor-the-agriculture-sector-11580484672637.html

Sabharwal, S. (2020, January 23). Budget 2020: Want to fix the slowing economy? FM Nirmala Sitharaman should begin with agriculture. Retrieved from https://www.businesstoday.in/unionbudget-2020/columns/budget-2020-fm-nirmala- sitharaman-should-begin-with-agriculture-sectorindian-economy-farmers/story/394482.html

Sharma, D. (2018, May 18). What you don't know about Aadhaar. Retrieved from https://economictimes.indiatimes.com/wealth/personal-finance-news/what-you-dont-knowabout-aadhaar/articleshow/64208401.cms

Stratfor. (2016, July 21). India Strains to Move Away From Agriculture. Retrieved March 10, 2020, from https://worldview.stratfor.com/article/india-strains-move-away-agriculture

Suneja, K. (2019, September 30). Agriculture share in India's 'Gross Value Added' fell to 17.9\% in FY17 from 18.6\% in FY14. Retrieved March 10, 2020, from https://economictimes.indiatimes.com/news/economy/agriculture/agriculture-share-in-indias- grossvalue-added-fell-to-17-9-in-fy17-from-18-6-in-fy14/articleshow/71367513.cms 